\title{
Climate change and a poleward shift in the distribution of the Pacific white-sided dolphin in the northeastern Pacific
}

\author{
Christian J. Salvadeo ${ }^{1,2, *}$, Daniel Lluch-Belda ${ }^{1}$, Alejandro Gómez-Gallardo ${ }^{2}$, \\ Jorge Urbán-Ramírez ${ }^{2}$, Colin D. MacLeod ${ }^{3}$ \\ ${ }^{1}$ Centro Interdisciplinario de Ciencias Marinas, IPN. A.P. 592. C.P. 23000 La Paz, Baja California Sur, Mexico \\ ${ }^{2}$ Universidad Autónoma de Baja California Sur, Carretera al Sur km 5.5, C.P. 23080 La Paz, Baja California Sur, Mexico \\ ${ }^{3}$ School of Biological Sciences (Zoology), University of Aberdeen, Tillydrone Avenue, Aberdeen AB24 3FX, UK
}

\begin{abstract}
Increasing water temperatures due to global warming mean that specific isotherms are shifting polewards. This may cause the poleward shifts in the range limits of species that are only found in specific thermal habitats. Such range shifts have been recorded in a number of plant and animal species. In the last 3 decades, we observed a decline in the presence of Pacific white-sided dolphin Lagenorhynchus obliquidens in the southwest Gulf of California (GOC), which is considered the southern boundary of their distribution. Considering that the thermal environment is physiologically important to animals, we believe that this poleward shift in the usual geographic range of the Pacific white-sided dolphin is due to long-term changes in the local climate. To obtain the conceptual framework needed to discuss such a hypothesis, we summarize and analyze current knowledge about Pacific white-sided dolphins in the southwest GOC, and sea surface temperature variability at a regional scale.
\end{abstract}

KEY WORDS: Climate change $\cdot$ Lagenorhynchus obliquidens $\cdot$ Poleward shift · Northeastern Pacific Gulf of California

Resale or republication not permitted without written consent of the publisher

\section{INTRODUCTION}

Climate change is affecting biodiversity and places additional pressures on already over-used, degraded, and fragmented ecosystems, undermining their resilience. In particular, some species, especially polar and mountain species, have already experienced severe range contractions as they try to remain within their preferred climatic envelopes by changing their distributions (Parmesan \& Yohe 2003, Root et al. 2003). Cetacean species' ranges are likely to change in a similar manner as a result of increases in water temperature. For individual cetacean species, it can be predicted whether their ranges will expand, shift poleward, or contract based on their current distributions and on the characteristics of the niches they occupy (MacLeod 2009). In particular, certain characteristics place some species at greater risk from such changes than others. These include a range that is restricted to non-tropical waters (including temperate species) and a preference for shelf waters such as shown by most porpoises and Lagenorhynchus species (MacLeod 2009). Such range shifts in response to climate change are most likely to be detected at the edge of the current distribution of a species, since this is where any changes are likely to occur first.

The Pacific white-sided dolphin Lagenorhynchus obliquidens is restricted to the temperate waters of the North Pacific Ocean, and does not occur in tropical and Arctic waters. In the eastern Pacific, large groups of this species are frequently seen in the California Current System (CCS; Leatherwood et al. 1984, Stacey \& 
Baird 1990, Keiper et al. 2005). The southern boundary of the distribution of Pacific white-sided dolphins is the Gulf of California (GOC), where the species has been observed only in the southwest area during the temperate season (from December to June; Aurioles et al. 1989).

In the CCS and GOC, water temperatures are known to have increased over the last century (Lluch-Belda et al. in press; see Fig. 2). Given this water temperature rise at the southern edge of its distribution, if the range of the Pacific white-sided dolphin is being affected by climate change in the manner suggested by MacLeod (2009), we would predict that its distribution would have declined in the GOC in recent years. To test this prediction, we examined the occurrence of Pacific white-sided dolphins in the GOC between 1980 and 2009 based on data from 2 separate sources. While these surveys have different spatial coverage, they provide data collected in a consistent manner for an overlapping area in the GOC over a sufficiently long period to assess whether any changes in distribution have occurred at the southern edge of this species' distribution in the northeast Pacific.
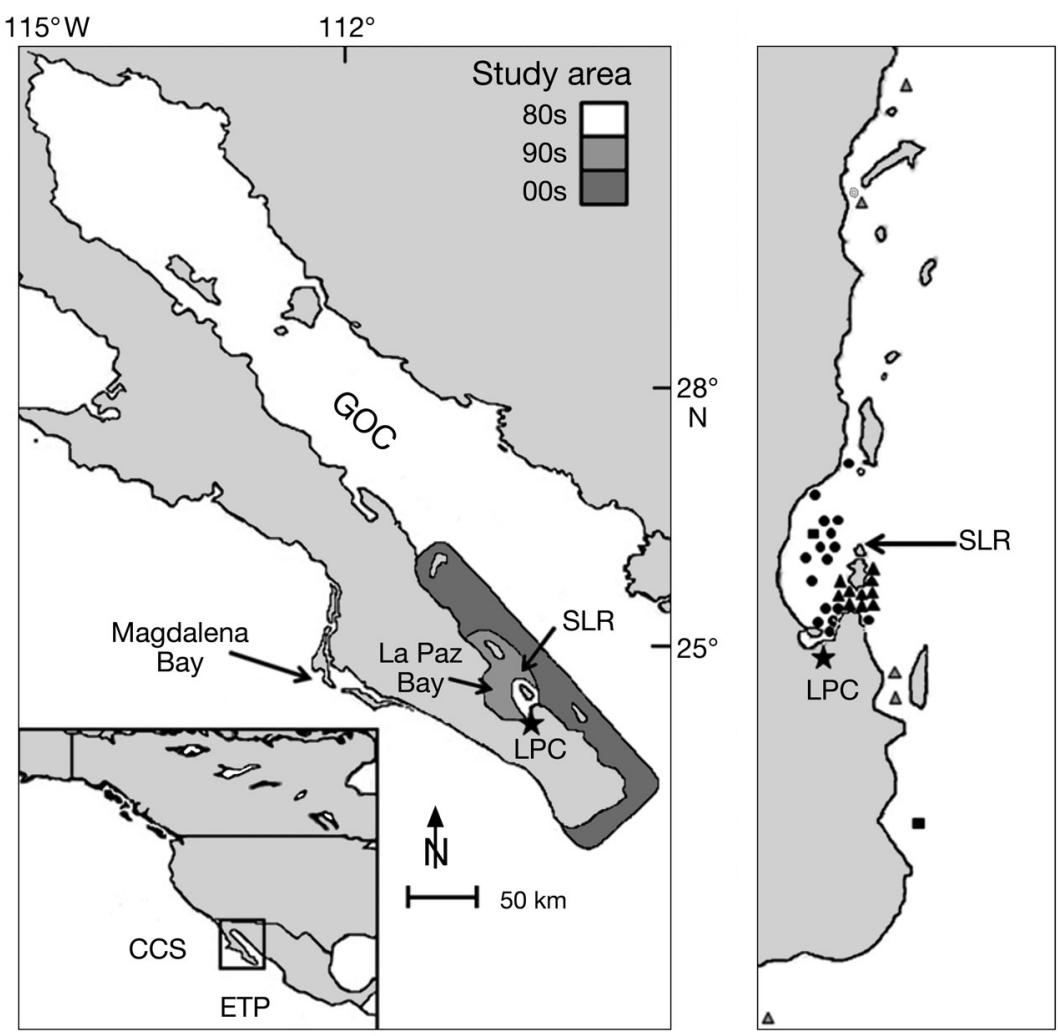

Fig. 1. Study area and sighting positions from 1978-1988 (80s) (small white area within dark gray shaded area; all triangles, where gray triangles indicate opportunistic sightings reported by Aurioles et al. 1988, 1989 and not taken in to account for numerical analysis), 1989-1999 (90s) (•), and 2000-2009 (00s) (ם). CCS: California Current System; ETP: Eastern Tropical Pacific; GOC: Gulf of California; LPC: La Paz City; SLR: sea lion rookery

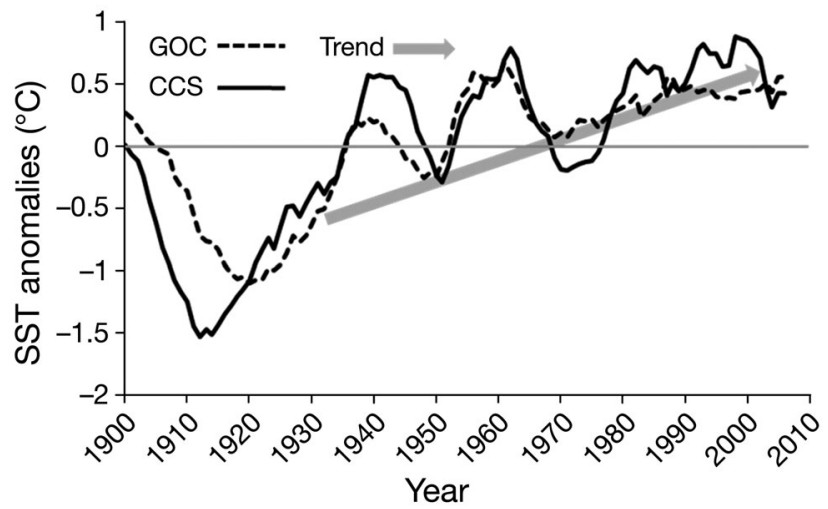

Fig. 2. Sea surface temperature (SST) anomalies (10 yr Hamming smoothed series) in the Gulf of California (GOC) and California Current System (CCS) from Lluch-Belda et al. (in press)

\section{MATERIALS AND METHODS}

The study area is located in the southwest GOC along the eastern coast of the Baja California Peninsula (Fig. 1). This area is structurally complex. The continental shelf is irregular and narrow with the presence of basins, sea mounts, and several volcanic islands. North-northwesterly winds prevail during the temperate season, promoting upwelling along the gulf's eastern coast (Maluf 1983). Such upwelling fertilizes the whole gulf through a system of eddies that carry enriched waters from the eastern to the western coast (Beier 1997). These hydrographic features promote a higher and homogeneously distributed productivity throughout the study area.

We compared sightings of the Pacific white-sided dolphin in the southwest GOC during temperate seasons (when this species is most likely to be present) from the last 3 decades. These sighting data came from 2 separate sources. We primarily used data from Aurioles et al. (1989) to provide information on the occurrence of Pacific white-sided dolphins in the surveyed area during the 1980s. These data were collected during trips to the sea lion rookery situated on Espiritu Santo Island in La Paz Bay (Fig. 1). During each trip, observers searched for animals and recorded all species sighted (D. Aurioles pers. comm.). These surveys were initiated in 1978 and have continued until the present time. The second data set used included sightings collected over a 20 yr period between 1989 
and 2009 by the Universidad Autónoma de Baja California Sur (UABCS). These sightings were collected during sampling trips that followed a consistent but non-random search method, in which the boat ran in a straight line at cruising speed (11 knots) following a predetermined track trying to cover most of the study area, with less than Beaufort 3 wind scale conditions (higher conditions significantly reduce the capacity of observers to detect cetaceans). During each sampling trip, 3 observers were located on the boat, 1 at the front and 1 on each side of the boat for cetacean searching, and stops were made every $30 \mathrm{~min}$ for a $360^{\circ}$ binocular $(7 \times 50)$ scan. When a cetacean was sighted, the date, time, species, location, number of animals, behavior, and association with other marine species (birds, fishes, mammals, and turtles) were recorded. For the purposes of this study, this data set was divided into 2 time periods, the 1990s and the 2000s. The 1990s data were obtained exclusively from sampling trips in the La Paz Bay area and adjacent waters, while in the 2000s, the area covered was larger (Fig. 1). While the data for the 1990s (1998-1999) and 2000s (2000-2009) came from larger sampling areas than those covered by the data from the 1980s (1978-1988), these later surveys also covered the same area as the 1980s surveys, meaning that there is at least some spatial consistency over time. In addition, as the Pacific white-sided dolphin is generally more abundant in open waters, this species is likely to be more abundant in these wider areas than in La Paz Bay itself. Therefore, the wider coverage would be expected to have increased rather than decreased the encounter rate with this species.

Sighting data from the UABCS surveys collected from 1989 to 2009 were used to calculate seasonal dolphin relative abundance (animals $\mathrm{h}^{-1}$ ) for each year as an indicator of the species' presence in GOC waters for the 1990s and 2000s. Data from Aurioles et al. (1989) were not included in this calculation, because they were presented as accumulated monthly observations from the period 1978 to 1988; thus we could not calculate the relative abundance and effort for each year alone. In addition, effort was presented as the number of transects. For this reason, before we were able to compare their data to the UABCS data, it was necessary to transform the number of transects into the total time spent ( $3 \mathrm{~h}$ for each transect; D. Aurioles pers. comm.).

To compare records among the 3 decades, for each we calculated the following: (1) the total effort hours, total sightings, and total number of animals; (2) the mean, maxima, and minima of the dolphin group size; and (3) the relative abundance (number of sightings and animals $\mathrm{h}^{-1}$ of effort). Also, the monthly accumulated effort and number of animals were calculated for the 1990 s and 2000 s, to compare the monthly presence pattern between decades.
To assess possible causes for any changes in the occurrence of Pacific white-sided dolphins, 3 additional data sets were investigated. Firstly, information on the occurrence of other cetacean species collected during the same surveys was investigated. This allowed an assessment of whether any decline in occurrence was restricted to the main species of interest, or whether other species were also affected. If only Pacific white-sided dolphins were affected, then this would suggest the change is unlikely to be driven by factors such as bycatch, changes in productivity, or decline in ecosystem productivity, which would be expected to also affect other cetacean species.

Secondly, data from annual landings of small pelagic fish (mostly Pacific sardine Sardinops sagax caerulea) in the GOC and the west coast of Baja Peninsula (Magdalena Bay and Ensenada) were used as an approximation of regional prey availability. We used annual sardine landings as they are considered a good index of sardine abundance, due to a high degree of similarity between sardine landings and biomass estimation (Norton \& Mason 2005). These data were provided by the Laboratorio de Edad y Crecimiento at the Centro Interdisciplinario de Ciencias Marinas-Instituto Politécnico Nacional (CICIMAR-IPN). This allowed us to assess whether changes in prey availability could be influencing the occurrence of Pacific white-sided dolphins within the surveyed areas.

Finally, in order to directly assess whether any changes in the occurrence of Pacific white-sided dolphins since the 1980s were related to changes in water temperature, data on sea surface temperature (SST) in the CCS and southern GOC region were obtained from Lluch-Belda et al. (in press). The authors constructed annually averaged sea surface temperature (SST) anomalies in $2 \times 2^{\circ}$ quadrants at the GOC and CCS using the International Comprehensive Ocean-Atmosphere Data Set (ICOADS, Release 2.0, available at http://icoads.noaa.gov/) and the NOAA Extended Reconstructed SST (ERSST) data set (NOAA Satellite and Information Service, http://lwf.ncdc.noaa. gov/oa/climate/research/sst/sst.php).

\section{RESULTS}

The data show that despite the increase in the spatial (Fig. 1) and temporal (Fig. 3, Table 1) effort, the occurrence (sightings and animals $\mathrm{h}^{-1}$ of effort ) of this dolphin species has decreased during the last 3 decades (Fig. 3, Table 1). This decline in occurrence is most evident at the decadal scale.

In the 1980s, Pacific white-sided dolphins were regularly sighted in the surveyed areas between La Paz City and the sea lion rookery in La Paz Bay (Fig. 1). 
Table 1. Lagenorhynchus obliquidens. Accumulated historical data from the southwest Gulf of California for the last 3 decades. Effort (h); sightings: number of occasions when the species was observed; mean, minimum (min.), maximum (max.), and SD for group size; sightings $\mathrm{h}^{-1}$ and animals $\mathrm{h}^{-1}$ : abundance relative to effort; 1980s: 1978-1988; 1990s: 1989-1999; 2000s: 2000-2009

\begin{tabular}{|cccccccccc|}
\hline Period & Effort & Sightings & Animals & Mean & Min. & Max. & SD & Sightings h $^{-1}$ Animals h $^{-1}$ \\
\hline $1980 \mathrm{~s}$ & 252 & 10 & 647 & 65 & 2 & 200 & 67 & 0.039 \\
$1990 \mathrm{~s}$ & 1659 & 16 & 316 & 20 & 1 & 45 & 12 & 0.010 & 2.56 \\
$2000 \mathrm{~s}$ & 1986 & 2 & 50 & 25 & 20 & 30 & 7 & 0.001 & 0.03 \\
\hline
\end{tabular}

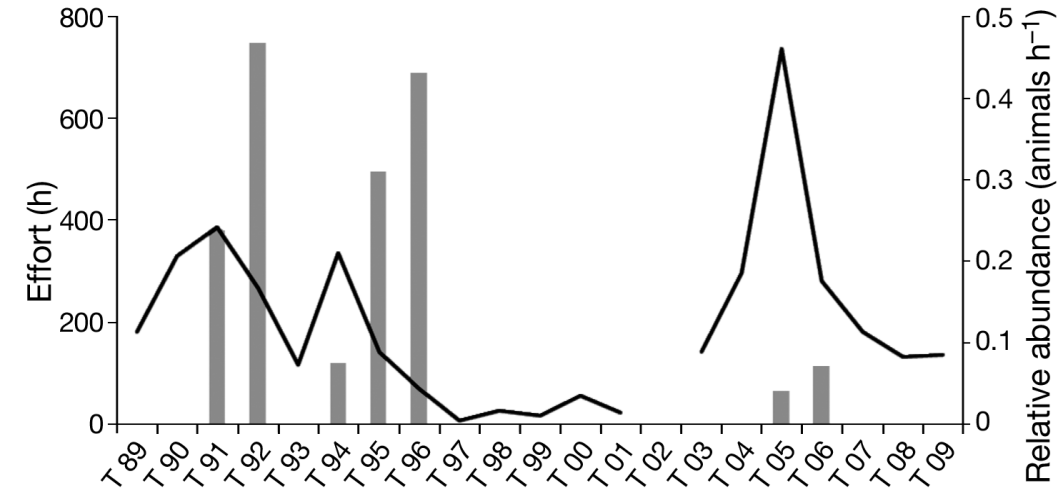

Fig. 3. Lagenorhynchus obliquidens. Relative abundance (animals $\mathrm{h}^{-1}$, gray bars) and effort ( $h$, black line) during the temperate season $(\mathrm{T}$, followed by the respective year)

They were recorded throughout the cold season from January to June (Figs. 4 \& 5). For the 1980s as a whole, the sighting rates and relative abundance were 0.039 and $2.56 \mathrm{~h}^{-1}$ of effort, respectively. Group sizes ranged from 2 to 200 with a mean of 65 animals.

During the 1990s, Pacific white-sided dolphins were recorded between February and May (Figs. 4 \& 5) in groups between 1 and 45 animals (mean: 20). The sighting rate was $0.01 \mathrm{~h}^{-1}$, and the relative abundance was 0.19 ind. $\mathrm{h}^{-1}$ of survey effort for the area surveyed. In addition, there were few sightings recorded within the area covered during the 1980s surveys (Fig. 1).

In the 2000s, only 2 groups of Pacific white-sided dolphin were recorded, 1 of 20 animals and 1 of 30 ani-

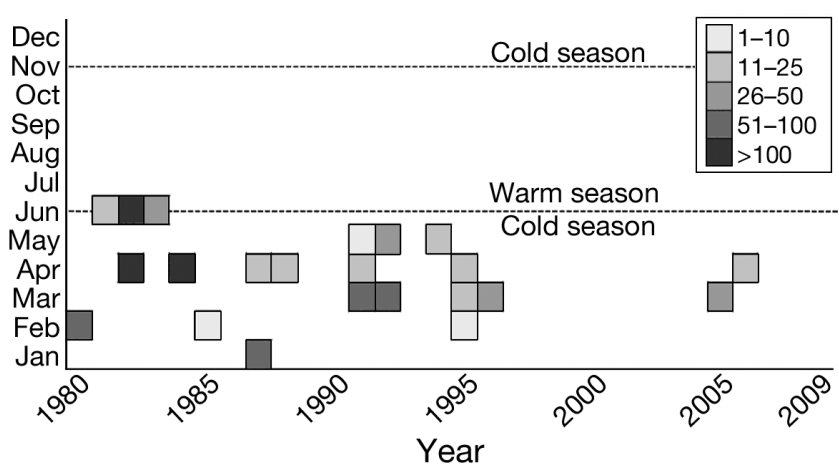

Fig. 4. Lagenorhynchus obliquidens. Historical number (total) of dolphins sighted per month in the surveyed areas (see Fig. 1) mals. These sightings occurred in March and April, respectively. The sightings rate was 0.001 groups $\mathrm{h}^{-1}$ of survey effort, and the relative abundance was 0.03 ind. $\mathrm{h}^{-1}$. In addition, no sightings were recorded in the area that had been surveyed in the 1980s (Fig. 1).

Therefore, based on these data sets, 3 changes in the occurrence of Pacific white-sided dolphins in the GOC over time can be identified. These are: (1) a decrease in seasonal occurrence from the entire cool season (January to June) in the 1980s to only the central months of the cool season (March and April) in the 2000s; (2) a decrease in maximum and average group sizes from 200 and 65 animals, respectively, in the 1980 s to 30 and 25, respectively, in the $2000 s_{;}$(3) a decrease in sighting rates and relative abundances from 0.039 sightings and 2.56 ind. $\mathrm{h}^{-1}$ of survey effort in the 1980 s to 0.001 sightings and 0.03 ind. $\mathrm{h}^{-1}$ of survey effort in the $2000 \mathrm{~s}$. While some of these changes could have resulted from a change in survey coverage between the 3 time periods, when only the area covered in 1980s was compared, this change is still evident, with half as many sightings during the 1990s as during the 1980s and none during the 2000s.

Other cetacean species encountered in the study area included common dolphins Delphinus spp., bottlenose dolphin Tursiops truncatus, pilot whale Globicephala macrorhynchus, sperm whale Physeter macrocephalus, fin whale Balaenoptera physalus, Bryde's whale $B$. edeni, and as seasonal visitors the blue whale B. musculus and the humpback whale Megaptera novaeangliae. None of these other cetacean species show evidence of a similar decline (Salvadeo 2008, Troyo-Vega 2008, Pardo 2009). For example, common dolphins, which are warm-temperate water species not close to the edge of their range, have not changed in terms of their seasonal occurrence, group size, or relative abundance. In addition, the population of sea lions at La Paz Bay has grown in recent years (Szteren et al. 2006). This suggests that the observed changes in Pacific white-sided dolphin occurrence are not driven by ecosystem factors such as changes in productivity. 

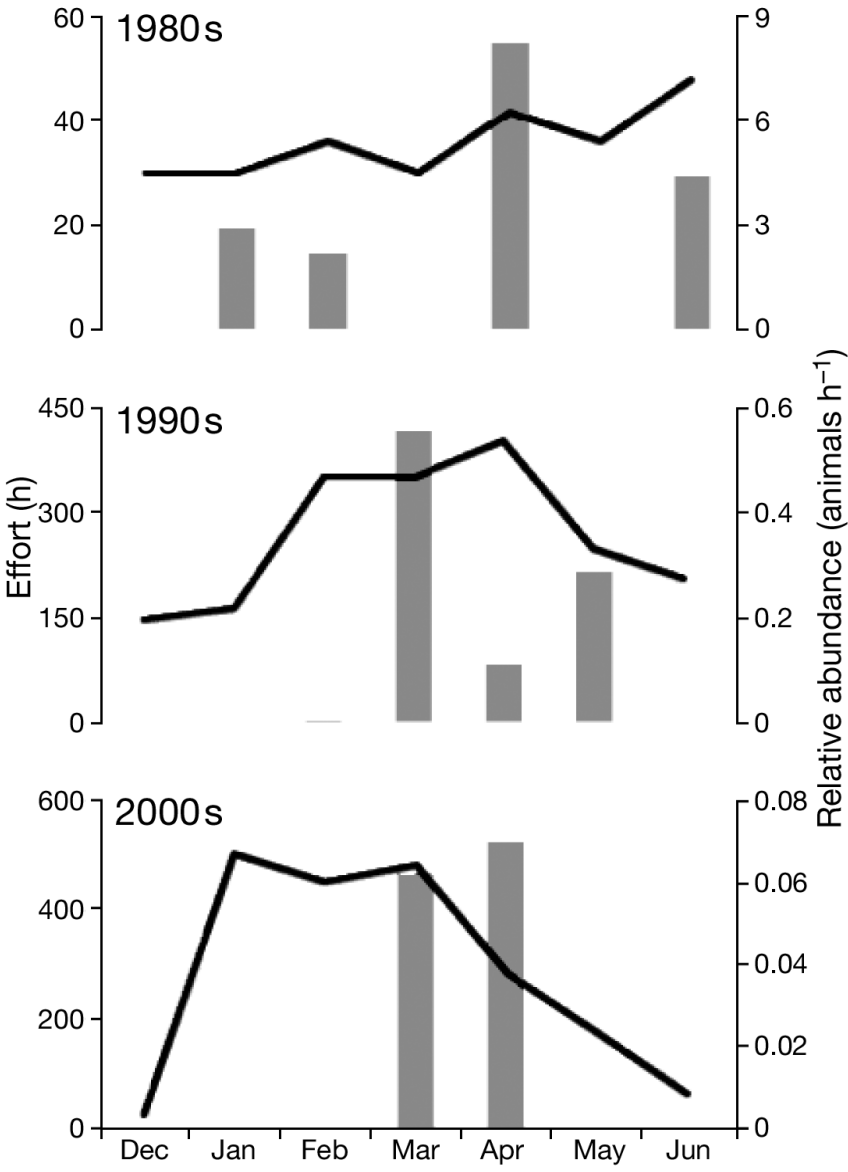

Fig. 5. Lagenorhynchus obliquidens. Accumulated relative abundance (animals $\mathrm{h}^{-1}$, gray bars) and effort ( $\mathrm{h}$, black line) per month for each decade. Note the different scales

Similarly, sardine landings in the GOC did not show a consistent decline between the 1980s and the 2000s. Instead, they showed a decline between 1989 and 1993, followed by an increase from 1993 to 2007 (Fig. 6). Sardine landings from neighboring areas out-

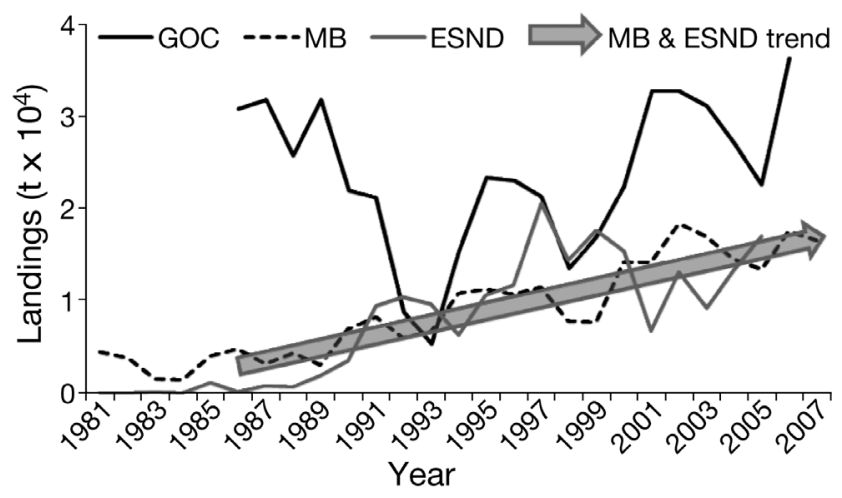

Fig. 6. Annual sardine landings from the Gulf of California (GOC) and from the west coast of Baja Peninsula represented by Magdalena Bay (MB; see Fig. 1) and Ensenada (ESND) located near the USA border; MB and ESND data were multiplied by 3 for comparative purposes side the GOC showed a consistent increase from the 1980 s to 2007. Therefore, the changes in the occurrence of Pacific white-sided dolphins in the GOC did not occur in concert with a decline in local fish stocks.

In terms of water temperatures, there has been a trend to increasing water temperatures in the GOC and the CCS since the mid-1910s (Fig. 2). This is consistent with the observed changes in the Pacific whitesided dolphin occurrence being related to an increase in water temperatures.

\section{DISCUSSION}

In the Northeastern Pacific, there are several Pacific white-sided dolphin populations that show relatively complex patterns in their seasonal distributions. However, north-south and inshore-offshore movements have been recorded in several areas. These seasonal patterns are thought to be related to seasonal movements in prey species and changes in water temperature (Leatherwood \& Walker 1982, Aurioles et al. 1989, Stacey \& Baird 1990, Reeves et al. 2002, Keiper et al. 2005). In the southwest GOC, Aurioles et al. (1989) considered the Pacific white-sided dolphin to be a seasonal visitor during the temperate season (winter to spring; Figs. 4 \& 5), when the cooling of GOC waters allows them to enter from the CCS. In addition, their seasonal presence in the southwestern GOC matches with high abundances of small pelagic fish (potential prey) due to seasonal movement of sardine inside the GOC (Hammann et al. 1998). These small pelagic fishes, in turn, attract fish-eating predators such as small cetaceans and sea birds to the southwest GOC (Salvadeo 2008).

Our study suggests that the occurrence of the Pacific white-sided dolphin has decreased by approximately 1 order of magnitude per decade since the 1980s, (Figs. 3 $\& 5$, Table 1). This difference remains even if only areas surveyed in all 3 decades (La Paz Bay) are considered. For example, Pacific white-sided dolphins were rarely recorded in the area around La Paz during the survey conducted here since the year 2000 (Fig. 1). In addition, Pacific white-sided dolphins have not been sighted during recent trips to the sea lion rookery, where data were collected in the 1980s (D. Aurioles pers. comm.).

This decline in the occurrence of Pacific white-sided dolphins in the GOC has not been associated with declines in other marine mammals, such as common dolphins or California sea lions from the La Paz Bay colony, nor has it been associated with a decline in sardine landings (a good index of sardine biomass). This suggests that the decline in Pacific white-sided dolphin occurrence is not related to factors such as a decline in available prey or a reduction in productivity. In addi- 
tion, the level of bycatch in Pacific white-sided dolphins is relatively low $(<10 \%$ of calculated biological removal; Carretta et al. 2008), and therefore is unlikely to be a major driving force behind the decline in occurrence that we identified in this study. Similarly, there is no evidence of increased industrial or military noise within the region that could contribute to this decline. Finally, the principal activities in the southern peninsula are artisanal and sport fisheries, and ecotourism; these activities have a low or no impact on marine mammals around the area.

However, the decline in occurrence has occurred during a period of warming in the local region. This suggests that changes in water temperature may be associated with the decline in occurrence. This possibility is further supported by the seasonal contraction in occurrence to the coolest times of the year as temperatures have increased.

While variations in water temperature may be associated with short-term climatic events, such as El Niño and Pacific Decadal Oscillations (PDO), there has been a consistent increase in temperature throughout the period from 1980 to 2009. This suggests that the main driving force behind these changes in water temperature is global climate change rather than more regional and mid-term climatic events.

Thus, if we consider the GOC as the southern boundary of the Pacific white-sided dolphin range, the decrease in their abundance and group size between 1980 and 2009 (Table 1, Figs. 3 to 5) and their monthly contraction to cooler months (Figs. 4 \& 5), are evidence consistent with a poleward shift in their range.

Therefore, these observations are consistent with the northward shift in the range of the Pacific white-sided dolphin predicted by MacLeod (2009). This possibility of a poleward shift in the range of the Pacific whitesided dolphin in the northeastern Pacific is further supported by evidence that Pacific white-sided dolphins increased in occurrence on the west coast of Canada from 1984 to 1998 (Morton 2000). Therefore, throughout the northeast Pacific, there is evidence of a poleward shift in occurrence at both the northern and southern range limits of this species, associated with increases in water temperature.

This poleward shift in the range of the Pacific whitesided dolphin in response to climate change is likely to have implications for conservation and management of the GOC marine environment. In particular, the species' shift away from the GOC may be indicative of other climate-induced changes in local ecosystems. In addition, it has implications for the conservation and management of the Pacific white-sided dolphin in the northeastern Pacific. In particular, it is likely to become increasingly rare in southern portions of its current range, especially in Mexican waters.
Finally, this is the second of the 6 species of the genus Lagenorhynchus in which evidence of a climate change-induced range shift has been identified (MacLeod et al. 2005), supporting the hypothesis that members of this genus may be particularly at risk from the negative effects of climate change (MacLeod 2009).

Acknowledgements. We acknowledge the Consejo Nacional de Ciencia y Tecnología (CONACyT) and the Programa Institucional de Formación de Investigadores from the Instituto Politécnico Nacional (PIFI-IPN) for the scholarships given to C.S. We also thank the Cetacean Society International for a student grant. Thanks to the Marine Mammal Laboratory (UABCS) for the dolphin sighting data, The School for Field Studies and Ecology Project International (campus La Paz) for their support in the 1990s and 2000s field trips, respectively, C. Quiñónez-Velázquez for sardine data, M. Mercuri and G. de la Cruz-Aguero for comments, A. Gedissman for reviewing the English, and the anonymous reviewers for helping us to improve the paper.

\section{LITERATURE CITED}

Aurioles D, Leatherwood S, Muñoz E (1988) Pacific whitesided dolphins (Lagenorynchus obliquidens) in the Sea of Cortez. Bull South Calif Acad Sci 87:44-45

Aurioles DG, Gallo-Reynoso JP, Muñoz EL, Ejido JV (1989) El delfín de costados blancos (Lagenorhynchus obliquidens, Gill 1865) (Cetacea: Delphinidae) residente estacional en el suroeste del Golfo de California, México. An Inst Biol Univ Nac Auton Mex Zool 60:459-472

Beier E (1997) A numerical investigation of the annual variability in the Gulf of California. J Phys Oceanogr 27: 615-632

Carretta JV, Forney KA, Lowry MS, Barlow J and others (2008) United States Pacific marine mammal stock assessment: 2008. NOAA Tech Memo NMFS-SWFSC-434

Hammann MG, Nevárez-Martínez MO, Green-Ruíz Y (1998) Spawning habitat of the Pacific sardine (Sardinops sagax) in the Gulf of California: egg and larval distribution 1956-1957 and 1971-1991. CCOFI Rep 39:169-179

Keiper CA, Ainley DG, Allen SG, Harvey JT (2005) Marine mammal occurrence and ocean climate off central California, 1986 to 1994 and 1997 to 1999. Mar Ecol Prog Ser 289: 285-306

Leatherwood S, Walker WA (1982) Population biology and ecology of the Pacific whitesided dolphin Lagenorhynchus obliquidens in the northeastern Pacific. Part I: Distribution, seasonal movements and abundance with a bibliography and summary of specimen material. NOAA, NMFS, SWFC Admin Rep LJ-82-18C

Leatherwood S, Reeves RR, Bowles AE, Stewart BS, Goodrich KR (1984) Distribution, seasonal movements and abundance of Pacific white-sided dolphins in the eastern North Pacific. Sci Rep Whales Res Inst 35:129-157

Lluch-Belda D, Del Monte Luna P, Lluch-Cota SE (in press) 20th century variability of the Gulf of California SST. CCOFI Rep

> MacLeod CD (2009) Global climate change, range changes and potential implications for the conservation of marine cetaceans: a review and synthesis. Endang Spec Res 7: $125-136$ 
MacLeod CD, Bannon SM, Pierce GJ, Schweder CS, Learmonth JA, Herman JS, Reid RJ (2005) Climate change and the cetacean community of north-west Scotland. Biol Conserv 124:477-483

Maluf LI (1983) The physical oceanography. In: Case TJ, Cody ML (eds) Island biogeography in the Sea of Cortez. University of California Press, Berkely, CA, p 26-45

Morton A (2000) Occurrence, photo-identification and prey of Pacific white-sided dolphins (Lagenorhynchus obliquidens) in the Broughton Archipelago, Canada 19841998. Mar Mamm Sci 16:80-93

Norton JG, Mason JE (2005) Environmental influences on California sardine abundance. CCOFI Rep 46:83-92

Pardo M (2009) Condiciones fisicoquímicas y biológicas que modulan la abundancia de cetáceos sobre la Cuenca Alfonso, Golfo de California. MSc thesis, CICIMAR-IPN, La Paz

Parmesan C, Yohe G (2003) A globally coherent fingerprint of climate change impacts across natural systems. Nature 421:37-42

Reeves RR, Stewart B, Clapham PJ, Powell JA (2002) National Audobon Society guide to marine mammals of the world.

Editorial responsibility: Giovanni Bearzi,

Milan, Italy
Knopf, New York, NY

Root TL, Price JT, Hall KR, Schneider SH, Rosenzweig C, Pounds JA (2003) Fingerprints of global warming on wild animals and plants. Nature 421:57-60

Salvadeo CJ (2008) Análisis de la comunidad de odontocetos y la relación con su ambiente en el extremo sur-occidental del Golfo de California, México (2003-2006). MSc thesis, CICIMAR-IPN, La Paz

Stacey PJ, Baird RW (1990) Status of the white-sided dolphin, Lagenorhynchus obliquidens, in Canada. Can Field Nat 105:219-232

Szteren D, Aurioles-Gamboa D, Gerber L (2006) Population status and trends of the California sea lion (Zalophus californianus californianus) in the Gulf of California, Mexico. In: Trites AW, Atkinson S, DeMaster D, Fritz L, Gelatt L, Wynne K (eds) Sea lions of the world. Alaska Sea Grant College Program, University of Alaska, Fairbanks, AK, p 369-384

Troyo-Vega V (2008) Distribución y diversidad de cetáceos en el extremo suroccidental del Golfo de California, 2005. MSc thesis, UABCS, La Paz

Submitted: July 13, 2009; Accepted: October 29, 2009 Proofs received from author(s): February 10, 2010 